\title{
Verification and validation of a simulation model for energy use in buildings
}

\author{
G. Kalogeras, C. Koulamas, A. Kalogeras \\ Industrial Systems Institute, ATHENA Research Center \\ Patras, Greece \\ \{gkalogeras, koulamas, kalogeras\}@isi.gr \\ A. Moronis \\ Technological Educational Institute of Athens \\ Athens, Greece \\ amoronis@teiath.gr
}

\begin{abstract}
Different modeling approaches address the problem of energy efficiency in the building sector, being a multi-parametric problem. Physical or white-box approaches describe physical phenomena with sets of equations, and offer high interpretability in physical terms. Present work deals with a calculation-based monthly quasi-steady state simulation model for energy use in buildings based on ISO 13790 standard methodologies and presents its implementation. Model verification and validation is performed according to procedures of EN 15265 standard and against a real hospital usecase.
\end{abstract}

\section{Keywords}

Building energy model, energy performance of buildings, quasi-steady state energy simulation model

\section{INTRODUCTION}

Buildings account for $20 \%$ of total energy consumption in the developed world [1]. Space conditioning and lighting represent top energy end-use in 2005 in U.S. residential and commercial buildings [2]. There are different parameters that influence overall energy consumption in buildings and its break down between end uses. Such parameters include meteorological conditions, occupant behavior, building characteristics, systems and appliances.

Modeling of building energy consumption and efficiency is a tool that allows quantification of energy consumption in buildings and its sharing among end uses. Different approaches may be followed to this end [3]. Physical or white box models start from physical laws and their analysis with reference to building different systems and their characteristics, and based on them calculate building energy consumption. There are three main calculation methods [4]: Computational Fluid Dynamics [5], Zonal and Nodal method.

On the other hand, Statistical of black box models rely on building data rather than physical building information and apply statistical techniques to predict building energy consumption. Main statistical techniques include multiple regression, Artificial Neural Networks and decision trees [6].

Finally, hybrid or grey box models present a combination of the above approaches. They start from the mathematical 
structure of physical or white box models and estimate their parameters through measured data. They are based on both calculations and measurements with the latter used to limit calculation discrepancies.

The availability and details of data significantly determine different types of approaches applicability. Physical models are highly interpretable in physical terms, yet present difficulties to adapt to different buildings as they incorporate a specific building individual characteristics. Statistical models results are difficult to interpret in physical terms, yet do not require an in depth knowledge of the building under modeling. Hybrid model results offer good interpretability, yet their exploitation of two distinct domains may increase degree of difficulty of their understanding.

Present work is related with a white-box calculation based monthly quasi-steady state simulation model of building energy consumption based on ISO 13790 [7]. An implementation of this model is verified and validated following a methodology employing the procedures of EN 15265 [8] and a real hospital usecase. Further validation of the model is done with reference to model robustness checking.

The paper is organized as follows. Chapter II presents the quasi steady state monthly model and its validation results with reference to the EN 15265 standard, Chapter III deals with its validation against a real hospital usecase. Chapter IV presents the model validation in terms of model robustness checking. Chapter $V$ presents a discussion and conclusions.

\section{The QuASI-STEAdy StATE Monthly Model}

Calculating building energy consumption according to ISO 13790 takes into account the different building systems comprising heating and cooling, lighting and appliances. With reference to heating and cooling the building is divided into different zones. Different set points may be applied for heating and cooling per zone. The energy need is defined as the heat to be added or extracted from the building so as to meet the heating and cooling set point requirements per zone. The quasi steady state model calculates the energy need for heating and cooling for each time step and each building zone. In the monthly method time step defined is a month. Basic equations of the quasi steady state monthly model are presented in [9].

EN 15265 presents general criteria and validation procedures for calculation methods for design and evaluation of thermal and energy performance of buildings and building components. It gives a set of 12 test cases as well as reference values for the results. All test cases use a single room for testing. The internal dimensions of the room are: length = 3,6 $\mathrm{m}$; depth = 5,5 $\mathrm{m}$; height $=2,8 \mathrm{~m}$. There is only one external wall with a window facing West. The window is a double pane glazing with an external shading device (Fig 1).

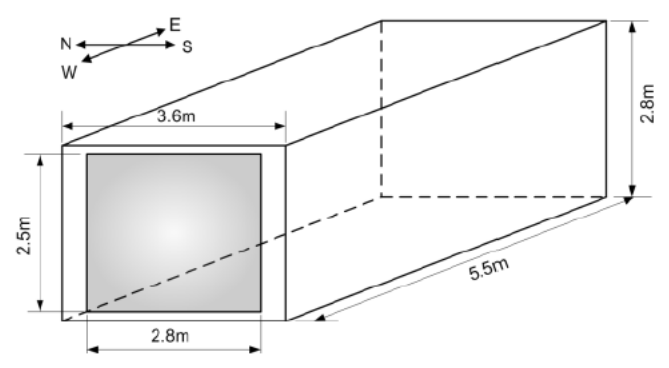

Fig. 1. EN 15265 single space for testing 


\begin{tabular}{|c|c|c|c|c|}
\hline \begin{tabular}{l|} 
Test \\
Case
\end{tabular} & Glazing & Ceiling /Floor & $\begin{array}{c}\text { Internal } \\
\text { gains }\end{array}$ & Operation \\
\hline 1 & Shaded & $\begin{array}{c}\text { Type } 4 \\
\text { Adiabatic } \\
\end{array}$ & $20 \mathrm{~W} / \mathrm{sqm}$ & Continuous \\
\hline 2 & Shaded & $\begin{array}{c}\text { Type } 3 \\
\text { Adiabatic }\end{array}$ & $20 \mathrm{~W} / \mathrm{sqm}$ & Continuous \\
\hline 3 & Shaded & $\begin{array}{c}\text { Type } 4 \\
\text { Adiabatic }\end{array}$ & 0 & Continuous \\
\hline 4 & Unshaded & $\begin{array}{c}\text { Type } 4 \\
\text { Adiabatic }\end{array}$ & $20 \mathrm{~W} / \mathrm{sqm}$ & Continuous \\
\hline 5 & Shaded & $\begin{array}{c}\text { Type } 4 \\
\text { Adiabatic }\end{array}$ & $20 \mathrm{~W} / \mathrm{sqm}$ & $\begin{array}{c}\text { Weekdays } \\
10 \mathrm{~h} / \text { day }\end{array}$ \\
\hline 6 & Shaded & $\begin{array}{c}\text { Type } 3 \\
\text { Adiabatic }\end{array}$ & $20 \mathrm{~W} / \mathrm{sqm}$ & $\begin{array}{c}\text { Weekdays } \\
10 \mathrm{~h} / \text { day }\end{array}$ \\
\hline 7 & Shaded & $\begin{array}{c}\text { Type } 4 \\
\text { Adiabatic }\end{array}$ & 0 & $\begin{array}{c}\text { Weekdays } \\
10 \mathrm{~h} / \text { day }\end{array}$ \\
\hline 8 & Unshaded & $\begin{array}{c}\text { Type } 4 \\
\text { Adiabatic }\end{array}$ & $20 \mathrm{~W} / \mathrm{sqm}$ & $\begin{array}{c}\text { Weekdays } \\
10 \mathrm{~h} / \text { day }\end{array}$ \\
\hline 9 & Shaded & $\begin{array}{c}\text { Type } 5 \\
\text { External roof }\end{array}$ & $20 \mathrm{~W} / \mathrm{sqm}$ & $\begin{array}{c}\text { Weekdays } \\
10 \mathrm{~h} / \text { day }\end{array}$ \\
\hline 10 & Shaded & $\begin{array}{c}\text { Type } 4 \\
\text { External roof } \\
\end{array}$ & $20 \mathrm{~W} / \mathrm{sqm}$ & $\begin{array}{c}\text { Weekdays } \\
10 \mathrm{~h} / \text { day } \\
\end{array}$ \\
\hline 11 & Shaded & $\begin{array}{c}\text { Type } 5 \\
\text { External roof }\end{array}$ & 0 & $\begin{array}{c}\text { Weekdays } \\
10 \text { h/day }\end{array}$ \\
\hline 12 & Unshaded & $\begin{array}{c}\text { Type } 5 \\
\text { External roof }\end{array}$ & $20 \mathrm{~W} / \mathrm{sqm}$ & $\begin{array}{c}\text { Weekdays } \\
10 \mathrm{~h} / \text { day }\end{array}$ \\
\hline
\end{tabular}

Table 1. EN 15265 Test Cases

The set of 12 Test Cases in EN15265 consists of 4 initial tests and 8 validation tests. The 4 initial tests are used to check the basic operation of the calculation method while the first case is the reference for all remaining. Table 1 presents characteristics of the 12 test cases. With reference to ceiling elements, Type 3 and 5 present higher mass, i.e. higher heat capacity, than Type 4 elements. The model was tested thoroughly by running a number of different simulations. The model algorithm was fine-tuned between each simulation in order to achieve the best match with the reference values as given in EN15265. The testing procedure aimed at achieving a relative error lower than $15 \%$ in all test cases (Fig. 2).

\section{VALIdATION Against A ReAl Hospital USECASE}

For the purposes of further validation of the model a real hospital usecase was utilized. Hospital data was derived from a hospital building audit. Then this data was fed as input into the model and simulations were executed.

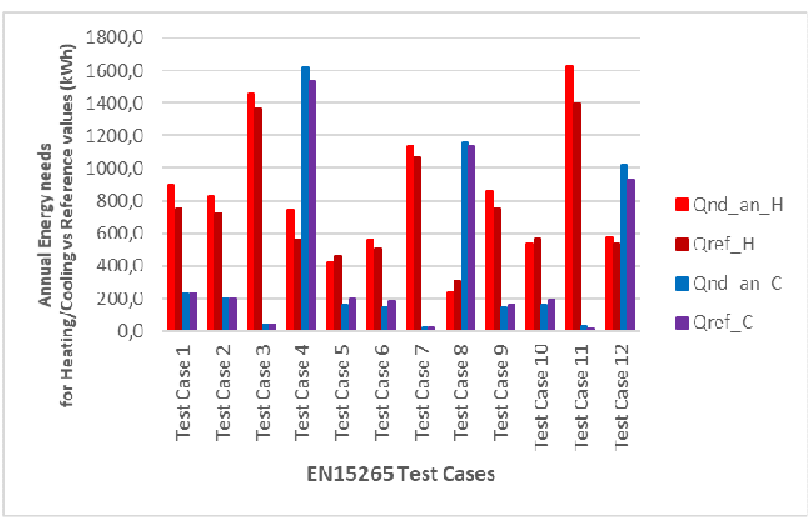

Fig. 2. Model Validation results with reference to EN 15265 test cases 


\section{A. Building Envelope Data}

The first section of data refers to the building envelope. It describes each external construction element in detail in terms of geophysical and thermo-physical properties. External elements include all construction elements (walls, roof, floor) and glazed elements. The building is divided into different zones depending on usage and properties of the HVAC system. Each zone is divided into different areas. Each area has different usage, such as offices, medical laboratories, patient rooms, operating rooms etc. The partitioning of each building zone according to area use is useful since each hospital area has different needs for ventilation, heating, cooling, lighting and different occupancy values.

Following the description of building zones, data related to opaque construction element are utilized. Each element must be associated with the zone it belongs to. The element external dimensions are used to calculate the element area. The element $U$ factor represents its thermal transmittance. Different construction materials have different $\mathrm{U}$ values. For each opaque element, its orientation (azimuth value in degrees), tilt in degrees (90 degrees for a vertical wall) and boundary conditions factor, which describes whether it is in contact with external air or not, are defined. Absorption coefficient is determined by the element coating, while emissivity has to do with the construction material type. Finally, shading factor is a reducing coefficient with a value of 1 for absence of any shading and 0 when an element is completely shaded.

Further to opaque elements, glazed element data has to be supplemented. Similar to opaque elements, dimensions of each glazed element are needed to calculate its area. $U$ factor, element orientation, tilt angle and boundary conditions are likewise needed. Further parameters include frame ratio compared to total window area, solar transmittance of glazed frames and shading factors.

\section{B. Occupancy Data}

Occupancy parameters in medical facilities play an important role in predicting building energy behavior as they represent significant internal gains that reduce the need for heating and increase the need for cooling during different seasons throughout a year. Therefore great care should be devoted to input accurate occupancy parameters. A first occupancy parameter is number of persons per area unit. Another one is working hours of each section in the hospital, meaning both number of working hours per weekday and number of working hours per weekend. These values are used to calculate operating time of various subareas in the facility.

\section{HVAC Data}

Hospital Heating, Cooling and Ventilation system has to be described. The main input value related to the ventilation system is number of air changes per hour. Each section of the building has different values depending on the need for fresh air and regulations related to that. In case or air recirculation, relevant data should be provided as well. The hours of operation of the ventilation system per section is also provided. This value is usually the same as the working hours of the hospital as described in occupancy.

The ventilation system treats the air before pumping it into the building. This treatment involves air preheating in winter and precooling in summer. Preheating and precooling set points are model input parameters. If there is a heat recovery system, the model's user should input the system efficiency factor as indicated in the technical datasheets of the ventilation unit. A final parameter that has to do with the ventilation system is energy consumption rate $\left(\mathrm{kW} / \mathrm{m}^{3} / \mathrm{s}\right)$, necessary to calculate energy consumption for building ventilation. Heating and cooling system is a crucial part of any building energy performance. The most important values related to the operation of the system to be gathered are heating and cooling set points, representing target temperatures for building internal spaces for winter and summer conditions.

It is important to provide the model also with details on heating and cooling system working hours in the form of hours/day and days/week. Crucial information on the efficiency of heating and cooling units are Coefficient of Performance and Energy Efficiency Ratio. The system distribution network losses can be calculated from the building technical drawings by finding the length of the network in contact with external air and multiplying it with the loss per length unit which can be found in international standards. From technical datasheets of terminal units, such as fan coils, the efficiency and the power consumption 
of the unit in question may be obtained.

\section{Lighting and Electrical Equipment}

The lighting of the facility and the electrical equipment installed in the hospital account for a hefty part of the electrical consumption of a medical facility. They also represent internal gains that affect the heating and cooling process. Lighting power is input as density per area unit for each section of the building. A distinction has to be made between lighting loads in areas that are heated/cooled or not. This happens because in heated/cooled areas the lighting system affects HVAC system operation by introducing internal gains whereas in non-heated/cooled areas only the electrical consumption is important. Moreover, lighting in building exterior is input separately since exterior lighting follows a different schedule from building interior. Data on the rated power of the installed equipment in all building areas is also needed. This equipment follows the usage created by facility working hours pattern. It has to be noted that hospitals use imaging equipment that has different usage characteristics from the rest of the electrical equipment. Namely imaging and diagnostic equipment has very high rated power values but is used for very short periods of time. Therefore, it is associated with rated power values and number of working hours per day.

\section{E. Weather Data}

The final set of input data required for the model to simulate a building energy performance is related to weather conditions in the area that the facility is situated. Average monthly temperatures are required together with monthly values of solar irradiance for each orientation and tilt of external element surfaces. External temperature can be obtained from external sources that utilize weather stations in the area of interest. As for solar irradiance, the calculation of monthly values for a certain tilt and angle is a complex procedure that requires access to hourly values of direct and diffused solar irradiance for an entire year in the area. This type of data can be obtained from online weather data services or from the weather data provided by dynamic simulators, such as the EnergyPlus tool [10].

\section{F. Validation Results}

The aforementioned data was inserted into the model and simulations were executed. The resulting estimated energy consumption data are well compared with actual hospital energy consumption data. Simulated results differ from actual values as presented in energy bills with percentages ranging from $2 \%$ to $25 \%$. The highest differences are recorded in summer months. These differences can be attributed to the fact that there is lack of a detailed record of hospital equipment and actual working schedule of each hospital section, making it difficult to accurately simulate the electricity consumption of the facility. It must also be noted that it is not possible to simulate the behavior of patients and hospital personnel, which can greatly affect the energy needs of the building, e.g. by operating windows during summer season. By comparing the total annual simulated energy with the total annual actual energy consumption we can see that there is a difference of $10.69 \%$ which is regarded as acceptable given the lack of complete data on hospital operation.

\section{Model Robustness CheCking Methodology}

Robustness testing is part of the validation process, testing the behavior of the system or model under exceptional execution conditions in order to determine whether or not it fulfils some robustness requirements. Informally, robustness is defined as the ability to maintain an "acceptable" behavior despite exceptional execution conditions or exotic input variable values [11]. "Acceptable" behavior is judged against robustness requirements that can be of a quite wide range.

When coming down to the energy performance of buildings models there is a quest to test the robustness of their precision both with reference to the overall model validation, but also with an eye to facilitating design and operation of energy efficient buildings. Model simulations are widely used as their results reflect actual measurements with high accuracy. Furthermore, they make possible experimentation with different parameters that could be difficult or even not feasible to control in practice, allowing to determine efficiency and exploit alternative designs without actual physical implementation. 


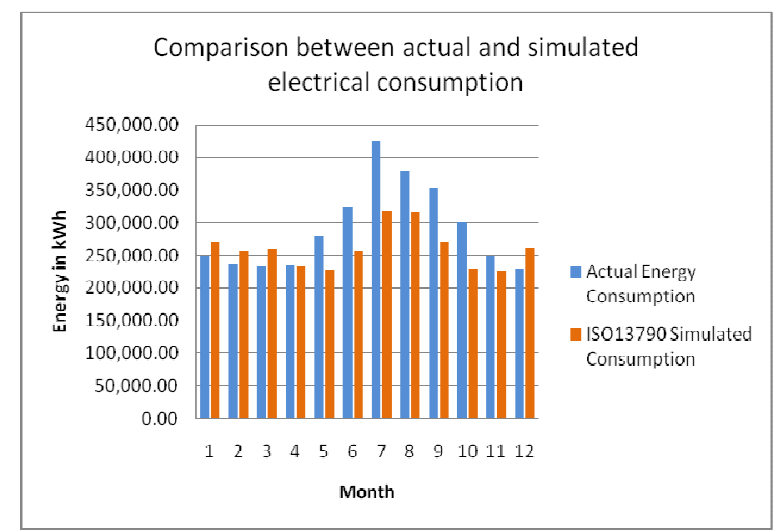

Fig. 3. Model Validation results with reference to actual hospital energy consumption data

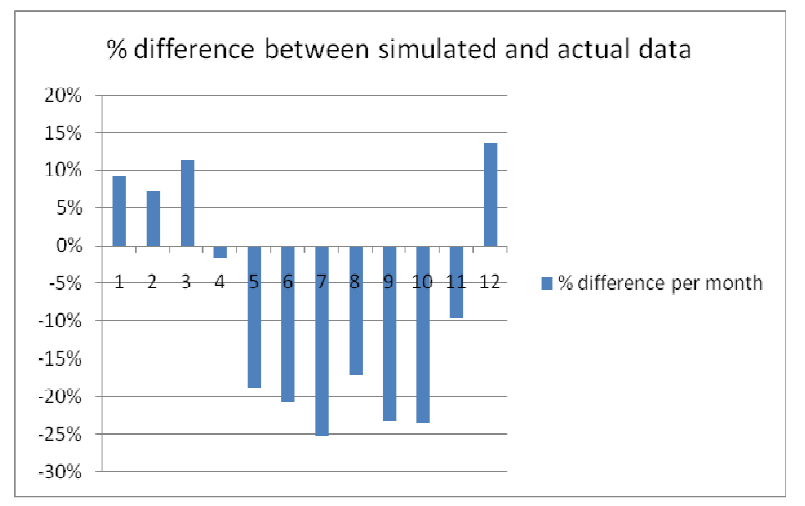

Fig. 4. Percentage difference between simulated and actual hospital data

In order to test the quasi steady state monthly model precision robustness, there is a need to examine its performance when a set of parameters is modified in a range of variables. This will be done against an interconnected EnergyPlus dynamic simulator model that will be used as a benchmark model [12]. This EnergyPlus model has been presented in [13]. A subset of parameters is selected for this purpose and a range of values for each one of them leading to a number of different cases. Simulation of these cases presents an adequate subset to perform the precision robustness check.

\section{DISCUSSION}

The paper presents the verification and validation results of a building energy efficiency quasi steady state monthly simulation model based on the EN 13790 standard. The validation is done first of all with reference to the EN 15265 usecases. Validation results present relative errors lower than $15 \%$ in all test cases. The validation is then done against the real building data of a hospital building. Data related to the building envelope, occupancy, HVAC system, lighting and electrical equipment, and weather are fed into the model. The validation results are well compared with actual hospital energy consumption data, giving a total error of approximately $11 \%$ when taking into account the total annual energy need. This error can be further reduced through acquisition of more accurate data on hospital operation and related electrical loads. In order to test precision robustness of the model, the EnergyPlus simulation is regarded as a benchmark. A set of parameters is selected to be modified in a predefined range of values, leading to different simulation cases. The relationships between the different variables, and their influence with reference to the overall model are assessed.

\section{ACKNOWLEDGEMENT}

This work is supported by the European Union Horizon 2020 Framework Program Marie Skłodowska-Curie Research and Innovation Staff Exchange (RISE) actions, under the project "Support Tool for Energy Efficiency pRogrammes in medical centres", ref. 645694, H2020-EU.1.3.3. 


\section{REFERENCES}

[1] U.S. Energy Information Administration, International Energy Outlook 2016, 2016.

[2] US Department of Energy, Energy Efficiency Trends in Residential and Commercial Buildings, 2008.

[3] Koulamas, C., Kalogeras, A. P., Pacheco-Torres, R., Casillas, J., \& Ferrarini, L. (2017). Suitability analysis of modeling and assessment approaches in energy efficiency in buildings. Energy and Buildings.

[4] A. Foucquier, S. Robert, F. Suard, L. Stéphan, A. Jay, State of the art in building modelling and energy performances prediction: A review, Renew. Sustain. Energy Rev. 23 (2013) 272-288. doi:10.1016/j.rser.2013.03.004.

[5] Tu, J., Yeoh, G. H., \& Liu, C. (2018). Computational fluid dynamics: a practical approach. Butterworth-Heinemann.

[6] G.K.F. Tso, K.K.W. Yau, Predicting electricity energy consumption: A comparison of regression analysis, decision tree and neural networks, Energy. 32 (2007) 1761-1768. doi:10.1016/j.energy.2006.11.010.

[7] ISO 13790 International Standard, "Energy performance of buildings - Calculation of energy use for space heating and cooling", https://www.iso.org/standard/41974.html

[8] EN 15265 European Norm, "Energy performance of buildings - Calculation of energy needs for space heating and cooling using dynamic methods - General criteria and validation procedures", https://standards.globalspec.com/std/1035831/din-en-15265

[9] A. Moronis, C. Koulamas and A. Kalogeras, "Validation of a monthly quasi-steady-state simulation model for the energy use in buildings," 201722 nd IEEE International Conference on Emerging Technologies and Factory Automation (ETFA), Limassol, 2017, pp. 1-6. doi: 10.1109/ETFA.2017.8247665

[10] Energy, U. D. (2016). EnergyPlus Engineering Reference. U.S. Department of Energy.

[11] Fernandez, Jean-Claude, Laurent Mounier, and Cyril Pachon. "A model-based approach for robustness testing." TestCom. Vol. 5. 2005.

[12] Kim, Young-Jin, Seong-Hwan Yoon, and Cheol-Soo Park. "Stochastic comparison between simplified energy calculation and dynamic simulation." Energy and Buildings 64 (2013): 332-342.

[13] C. Koulamas, A. Moronis, A. Kalogeras and D. Liberanome, "Choosing measures for energy efficient hospital buildings," 201722 nd IEEE International Conference on Emerging Technologies and Factory Automation (ETFA), Limassol, 2017, pp. 1-7. doi: 10.1109/ETFA.2017.8247666 